\title{
CATCH: a clinical decision rule for the use of computed tomography in children with minor head injury
}

\author{
Martin H. Osmond MD CM, Terry P. Klassen MD, George A. Wells PhD, Rhonda Correll RN, \\ Anna Jarvis MD, Gary Joubert MD, Benoit Bailey MD, Laurel Chauvin-Kimoff MD CM, \\ Martin Pusic MD, Don McConnell MD, Cheri Nijssen-Jordan MD, Norm Silver MD, Brett Taylor MD, \\ Ian G. Stiell MD; for the Pediatric Emergency Research Canada (PERC) Head Injury Study Group
}

Previously published at www.cmaj.ca

\section{ABSTRACT}

Background: There is controversy about which children with minor head injury need to undergo computed tomography (CT). We aimed to develop a highly sensitive clinical decision rule for the use of $\mathrm{CT}$ in children with minor head injury.

Methods: For this multicentre cohort study, we enrolled consecutive children with blunt head trauma presenting with a score of 13-15 on the Glasgow Coma Scale and loss of consciousness, amnesia, disorientation, persistent vomiting or irritability. For each child, staff in the emergency department completed a standardized assessment form before any CT. The main outcomes were need for neurologic intervention and presence of brain injury as determined by CT. We developed a decision rule by using recursive partitioning to combine variables that were both reliable and strongly associated with the outcome measures and thus to find the best combinations of predictor variables that were highly sensitive for detecting the outcome measures with maximal specificity.

Results: Among the 3866 patients enrolled (mean age 9.2 years), $95(2.5 \%)$ had a score of 13 on the Glasgow Coma Scale, $282(7.3 \%)$ had a score of 14, and $3489(90.2 \%)$ had a score of 15 . CT revealed that $159(4.1 \%)$ had a brain injury, and $24(0.6 \%)$ underwent neurologic intervention. We derived a decision rule for CT of the head consisting of four high-risk factors (failure to reach score of 15 on the Glasgow coma scale within two hours, suspicion of open skull fracture, worsening headache and irritability) and three additional medium-risk factors (large, boggy hematoma of the scalp; signs of basal skull fracture; dangerous mechanism of injury). The high-risk factors were $100.0 \%$ sensitive $(95 \% \mathrm{Cl} 86.2 \%-100.0 \%)$ for predicting the need for neurologic intervention and would require that $30.2 \%$ of patients undergo CT. The medium-risk factors resulted in $98.1 \%$ sensitivity ( $95 \% \mathrm{Cl} 94.6 \%-99.4 \%$ ) for the prediction of brain injury by $\mathrm{CT}$ and would require that $52.0 \%$ of patients undergo CT.

Interpretation: The decision rule developed in this study identifies children at two levels of risk. Once the decision rule has been prospectively validated, it has the potential to standardize and improve the use of $\mathrm{CT}$ for children with minor head injury.
$\mathrm{E}$ ach year more than 650000 children are seen in hospital emergency departments in North America with "minor head injury," i.e., history of loss of consciousness, amnesia or disorientation in a patient who is conscious and responsive in the emergency department (Glasgow Coma Scale score $\left.{ }^{1} 13-15\right)$. Although most patients with minor head injury can be discharged after a period of observation, a small proportion experience deterioration of their condition and need to undergo neurosurgical intervention for intracranial hematoma..$^{2-4}$ The use of computed tomography (CT) in the emergency department is important in the early diagnosis of these intracranial hematomas.

Over the past decade the use of CT for minor head injury has become increasingly common, while its diagnostic yield has remained low. In Canadian pediatric emergency departments the use of CT for minor head injury increased from $15 \%$ in 1995 to $53 \%$ in $2005.5,6$ Despite this increase, a small but important number of pediatric intracranial hematomas are missed in Canadian emergency departments at the first visit. ${ }^{3}$ Few children with minor head injury have a visible brain injury on CT (4\%-7\%), and only $0.5 \%$ have an intracranial lesion requiring urgent neurosurgical intervention. ${ }^{5,7}$ The increased use of CT adds substantially to health care costs and exposes a large number of children each year to the potentially harmful effects of ionizing radiation. ${ }^{8.9}$ Currently, there are no widely accepted, evidence-based guidelines on the use of $\mathrm{CT}$ for children with minor head injury.

\footnotetext{
From the Department of Pediatrics (Osmond), the Department of Epidemiology and Community Medicine (Wells) and the Department of Emergency Medicine (Stiell), University of Ottawa, Ottawa, Ont.; the Department of Pediatrics (Klassen, McConnell), University of Alberta, Edmonton, Alta.; the Clinical Research Unit (Correll), Children's Hospital of Eastern Ontario Research Institute, Ottawa, Ont.; the Department of Pediatrics (Jarvis), University of Toronto, Toronto, Ont.; the Department of Pediatrics (Joubert), University of Western Ontario, London, Ont.; the Department of Pediatrics (Bailey), CHU Sainte-Justine, Montréal, Que.; the Department of Pediatrics (Chauvin-Kimoff), McGill University, Montréal, Que.; Pediatric Emergency Medicine (Pusic), Columbia University Medical Center, New York, NY; the Department of Pediatrics (Nijssen-Jordan), University of Calgary, Calgary, Alta.; the Department of Pediatrics (Silver), University of Manitoba, Winnipeg, Man.; and the Department of Pediatrics (Taylor), Dalhousie University, Halifax, NS. The other members of the Pediatric Emergency Research Canada (PERC) Head Injury Study Group are listed in the Acknowledgements section.
}

CMAJ 2010. DOI:10.1503/cmaj.091421 
A clinical decision rule incorporates three or more variables from the history, physical examination or simple tests ${ }^{10.11}$ into a tool that helps clinicians to make diagnostic or therapeutic decisions at the bedside. Members of our group have developed decision rules to allow physicians to be more selective in the use of radiography for children with injuries of the ankle ${ }^{12}$ and knee, ${ }^{13}$ as well as for adults with injuries of the ankle, ${ }^{14-17} \mathrm{knee}^{18-20}$ head ${ }^{21,22}$ and cervical spine. ${ }^{23,24}$ The aim of this study was to prospectively derive an accurate and reliable clinical decision rule for the use of CT for children with minor head injury.

\section{Methods}

\section{Study setting and population}

We conducted a prospective cohort study in 10 Canadian pediatric teaching institutions and enrolled consecutive children (0-16 years of age) if they presented to one of the emergency departments after sustaining an acute minor head injury. Eligibility was based on patients having all of the following: (a) blunt trauma to the head resulting in witnessed loss of consciousness, definite amnesia, witnessed disorientation, persistent vomiting (two or more distinct episodes of vomiting 15 minutes apart) or persistent irritability in the emergency department (for children under two years of age); (b) initial score on the Glasgow Coma Scale in the emergency department of at least 13 , as determined by the treating physician; and (c) injury within the past 24 hours. Patients were excluded if they had obvious penetrating skull injury or obvious depressed fracture, acute focal neurologic deficit, chronic generalized developmental delay or head injury secondary to suspected child abuse. Patients who were returning for reassessment of a previously treated head injury and those who were pregnant were also excluded. The research ethics committee of each study hospital approved the study.

\section{Standardized assessment of patients}

Staff physicians in the emergency department who were certified in pediatrics, emergency medicine or family medicine or supervised residents (in their second year of training or above) assessed the patients. These physician assessors each underwent a one-hour training session on evaluating patients for 26 standardized clinical findings from the history, general examination and neurologic status. These potential predictor variables had been selected a priori by a team of investigators (M.H.O., T.P.K., A.J., G.J., B.B., L.C.-K., M.P., D.M., C.N.-J., B.T., I.G.S.) on the basis of a review of the existing literature and results of a pilot study. The assessors recorded the findings of the standardized assessment on data collection sheets before any CT. When it was feasible, a second emergency physician independently assessed each patient, to allow determination of interobserver agreement. For patients transferred from a primary care hospital, the study assessments took place after arrival at the study site.

\section{Outcome measures and their assessment}

The primary outcome was need for neurologic intervention, and the secondary outcome was brain injury on CT. The need for neurologic intervention was defined as either death within seven days secondary to the head injury or need for any of the following procedures within seven days: craniotomy, elevation of skull fracture, monitoring of intracranial pressure or insertion of an endotracheal tube for the treatment of head injury. Brain injury was defined as any acute intracranial finding revealed on $\mathrm{CT}$ that was attributable to acute injury, including closed depressed skull fracture (i.e., depressed past the inner table) and pneumocephalus but excluding nondepressed skull fractures and basilar skull fractures.

After the clinical examination, the treating physician determined whether the patient should undergo CT of the head. Staff radiologists at each site, who were blinded to the content of the data collection form, interpreted the CT scans. If the radiologist raised any uncertainty about whether an acute intracranial injury existed, then another radiologist and a neurosurgeon, both also blinded to the content of the data collection form, reviewed the CT scan. If uncertainty remained, the scan was considered negative.

Because not all patients with minor head injury routinely undergo CT at the study sites, we could not ethically mandate universal CT for all patients included in the study. Patients who did not undergo imaging were classified as having no clinically important brain injury if they met all of the following explicit criteria at 14 days, as determined during a structured interview conducted by telephone: headache absent or mild, complaints of memory or concentration problems absent, seizure or focal motor findings absent and return to usual daily activities (feeding, sleeping, school, play and work). A nurse who was unaware of the patient's predictor clinical variables assessed these criteria. Patients who did not meet these criteria returned for clinical reassessment and CT. Patients were classified as having brain injury solely on the basis of their CT findings. Patients who did not undergo CT and who could not be reached for follow-up were excluded from the final analysis.

\section{Statistical analysis}

We assessed the interobserver agreement for each variable using the kappa statistic and $95 \%$ confidence intervals (CIs). We did not calculate kappa values for variables created by cutpoint (e.g., amnesia $\geq 30$ minutes before injury) or for those collected from the medical record (e.g., age). We used univariable analyses with $\chi^{2}$ tests (or, for age, the $t$ test) to determine the strength of the association of these dichotomous variables with the primary outcome. We used recursive partitioning to combine variables that we found to be both reliable (kappa coefficient $>0.5$ ) and strongly associated with the outcome measures $(p<0.05)$ to find the best combinations of predictor variables that were highly sensitive for detecting the outcome measure while achieving the maximum possible specificity. Recursive partitioning creates a branching decision tree by dividing the patient population into subgroups with and without the outcome of interest according to the contents of predictor variables in the subgroup. We used KnowledgeSEEKER version 6.0 Software (Angoss Software International) for the recursive partitioning. Our previous experience suggested that recursive partitioning may be more suitable than logistic 
regression when the objective is to correctly classify one outcome group at the expense of the other (i.e., where high sensitivity is more important than overall accuracy).

We assessed the derived decision rule by comparing the classification of each patient with his or her actual status for the primary outcomes, which allowed us to estimate, with 95\% CIs, the sensitivity and specificity of the rule. The bootstrapping method $^{25}$ was used to evaluate the classification performance of the decision rule and to assess overfitting of the model.

\section{Results}

\section{Characteristics of the patients}

Between July 2001 and November 2005, we enrolled 3866 patients, all of whom underwent complete assessment of the primary outcome (Table 1, Table 2). Assessment of the secondary outcome, brain injury on $\mathrm{CT}$, reflected CT findings for $2043(52.8 \%)$ of the patients. The remaining $1823(47.2 \%)$ patients, who were all discharged directly from the emergency department, underwent the structured telephone inter-

Table 1: Characteristics of 3866 children with head injury

\begin{tabular}{|c|c|}
\hline Characteristic & $\begin{array}{c}\text { No. (\%) } \\
\text { of patients* }\end{array}$ \\
\hline \multicolumn{2}{|l|}{ Age, yr } \\
\hline Median (range) & $10(0-16)$ \\
\hline Interquartile range & $5-14$ \\
\hline Sex, male & $2505(64.8)$ \\
\hline $\begin{array}{l}\text { Time from injury to assessment by } \\
\text { physician, h, mean (SD) }\end{array}$ & $4.5(4.3)$ \\
\hline Arrived by ambulance & $1476(38.2)$ \\
\hline Transfer from another hospital & $665(17.2)$ \\
\hline Loss of consciousness (witnessed) & $1267(32.8)$ \\
\hline Disorientation or confusion (witnessed) & $2080(53.8)$ \\
\hline Amnesia $(n=2956)$ & $1730(58.5)$ \\
\hline Repeated vomiting ( $\geq 2$ episodes) & $1582(40.9)$ \\
\hline \multicolumn{2}{|l|}{ Initial score on Glasgow Coma Scale } \\
\hline 15 & $3489(90.2)$ \\
\hline 14 & $282(7.3)$ \\
\hline 13 & $95 \quad(2.5)$ \\
\hline \multicolumn{2}{|l|}{ Mechanism of injury } \\
\hline Fall & $1737(44.9)$ \\
\hline Sports & $872(22.6)$ \\
\hline Head struck or hit by object & $447(11.6)$ \\
\hline Bicycle-related & 334 (8.6) \\
\hline Pedestrian struck & 139 (3.6) \\
\hline Motor vehicle collision & 131 (3.4) \\
\hline Assault & $102(2.6)$ \\
\hline Motorized recreational vehicle & $83(2.1)$ \\
\hline Other & $21(0.5)$ \\
\hline
\end{tabular}

Note: $\mathrm{SD}=$ standard deviation

*Unless otherwise indicated. view with a registered nurse at 14 days after discharge for determination of the proxy outcome measure. Of all patients included in the study, $24(0.6 \%)$ underwent a neurologic intervention. CT revealed a brain injury in $159(4.1 \%)$ of the patients. The study sample included 277 children under two years of age, and 23 of these had brain injury revealed by CT. An additional 245 eligible patients were not included in the final analysis because they did not undergo CT or the telephone interview at 14 days to determine the proxy outcome measure. The characteristics of these patients were similar to those who underwent $\mathrm{CT}$ or the telephone interview to determine the proxy outcome measure. Another 2178 eligible patients were seen at the study sites but were not enrolled by the treating physicians. The characteristics of these nonenrolled patients were similar to those of patients who were enrolled, including mean age (8.4 v. 9.2 years), rate of arrival by ambulance $(35.3 \%$ v. $38.2 \%)$, transfer from another hospital $(15.9 \%$ v. $17.2 \%)$ and mechanism of injury.

\section{Predictor variables}

The variables with the highest associations with brain injury were those found on physical examination: suspected open or

Table 2: Management and outcomes for the 3866 patients

\begin{tabular}{|c|c|}
\hline Management or outcome & $\begin{array}{c}\text { No. }(\%) \\
\text { of patients* }\end{array}$ \\
\hline CT of head performed & $2043(52.8)$ \\
\hline Cases with follow-up by telephonet & $3122(80.8)$ \\
\hline Skull radiography performed & $182(4.7)$ \\
\hline \multicolumn{2}{|l|}{ Skull fracture } \\
\hline Linear & $167(4.3)$ \\
\hline Basal & $25(0.6)$ \\
\hline Acute brain lesion $\ddagger$ & $159(4.1)$ \\
\hline Epidural hematoma & $55(1.4)$ \\
\hline Cerebral contusion & $41(1.1)$ \\
\hline Pneumocephalus & $38(1.0)$ \\
\hline Subdural hematoma & $32(0.8)$ \\
\hline Depressed skull fracture & $28(0.7)$ \\
\hline Subarachnoid hemorrhage & $19(0.5)$ \\
\hline Intracerebral hematoma & $10(0.3)$ \\
\hline Diffuse cerebral edema & $6(0.2)$ \\
\hline Extra-axial hematoma (undifferentiated) & $6(0.2)$ \\
\hline Cerebellar hematoma & $3(0.1)$ \\
\hline Intraventricular hemorrhage & $1(0.03)$ \\
\hline Neurologic intervention§ & $24(0.6)$ \\
\hline Craniotomy & $20(0.5)$ \\
\hline Intubation for head injury & $6(0.2)$ \\
\hline Elevation of skull fracture & $2(0.1)$ \\
\hline Death secondary to head injury & 0 \\
\hline
\end{tabular}

Note: $\mathrm{CT}=$ computed tomography.

*Unless otherwise indicated.

tSome of these patients also underwent CT of the head.

‡Some patients had more than one lesion.

§Some patients had more than one intervention. 
depressed fracture; signs of basal skull fracture; large, boggy hematoma of the scalp; and low or deteriorating Glasgow Coma Scale score (Table 3, Table 4). The interobserver agreement ( $n=333$ cases) for some of the primary variables is given in Table 3 .

Combining variables using recursive partitioning analyses yielded a rule based on seven simple questions stratified as representing high risk and medium risk. The resulting rule (Box 1) is called the CATCH rule, for Canadian Assessment of Tomography for Childhood Head injury. Having any one of the four high-risk factors predicting the primary outcome, need for neurologic intervention, had a sensitivity of $100.0 \%$ (95\% CI 86.2\%-100.0\%) and a specificity of 70.2\% (95\% CI $68.8 \%-71.6 \%$ ) and would require that $30.2 \%$ of patients with minor head injury undergo CT (Table 5). The presence of any one of the four high-risk or three medium-risk factors in the rule would identify any CT-visible brain injury with a sensitivity of $98.1 \%(95 \%$ CI $94.6 \%-99.4 \%)$ and a specificity of $50.1 \%(95 \% \mathrm{CI} 48.5 \%-51.7 \%)$ and would require that $51.9 \%$ of patients with minor head injury undergo CT (Table 6). The three cases of brain injury that were not identified by this rule were an occipital skull fracture with a small pneumocephalus, mild brain edema and a small extra-axial hemorrhage (probably epidural) with a small cerebral contusion. None of these patients required treatment, and none had neurologic sequelae.

According to the bootstrapping results, the classification performance of the CATCH rules was accurate across 1000 bootstrapped test sets and was consistent with the estimation from the original data set. For the four high-risk factors for neurologic intervention, the sensitivity was $97.9 \%(95 \% \mathrm{CI}$ $97.8 \%-97.9 \%$ ) and the specificity was $70.2 \%$ (95\% CI 70.1\%-

Table 3: Association between variables (from history and physical examination) and presence of brain injury in children with a minor head injury (part 1 of 2)

\begin{tabular}{|c|c|c|c|c|}
\hline \multirow[b]{2}{*}{ Variable* } & \multicolumn{2}{|c|}{ Group; no. (\%) of patientst } & \multirow[b]{2}{*}{ OR $(95 \% \mathrm{Cl})$} & \multirow{2}{*}{$\begin{array}{l}\text { Interobserver } \\
\text { agreement, } \\
\text { kappa value } \\
n=333\end{array}$} \\
\hline & $\begin{array}{l}\text { Brain injury } \\
\quad n=159\end{array}$ & $\begin{array}{l}\text { No brain injury } \\
\quad n=3707\end{array}$ & & \\
\hline \multicolumn{5}{|l|}{ From history } \\
\hline Age, yr, mean (SD) & $8.3(5.2)$ & $9.2(5.0)$ & $-0.97 \ddagger(-1.74$ to -0.18$)$ & NA \\
\hline Sex, male (v. female) & $102(64.2)$ & $2403(64.8)$ & 0.97 (0.70 to 1.35$)$ & NA \\
\hline $\begin{array}{l}\text { Arrived by ambulance ( } v \text {. other mode } \\
\text { of transport) }\end{array}$ & $107(67.3)$ & $1369(36.9)$ & 3.51 (2.51 to 4.93$)$ & NA \\
\hline $\begin{array}{l}\text { Transferred from another health centre } \\
\text { (v. not transferred) }\end{array}$ & $54(34.0)$ & $611(16.5)$ & $2.61(1.86$ to 3.66$)$ & NA \\
\hline Loss of consciousness (witnessed) & $n=126$ & $n=3285$ & & \\
\hline $\begin{array}{l}\text { Any loss of consciousness (v. no loss of } \\
\text { consciousness) }\end{array}$ & $46(36.5)$ & $1221(37.2)$ & $0.97(0.67$ to 1.41$)$ & 0.67 \\
\hline $\begin{array}{l}\text { Loss of consciousness } \geq 1 \mathrm{~min} \\
\text { ( } \mathrm{v} \text {. no loss of consciousness or loss of } \\
\text { consciousness }<1 \mathrm{~min} \text { ) }\end{array}$ & $28(22.2)$ & $577(17.6)$ & 1.34 (0.87 to 2.06$)$ & NA \\
\hline Amnesia & $n=101$ & $n=2855$ & & \\
\hline Any (v. none) & $70(69.3)$ & $1660(58.1)$ & $1.74(1.12$ to 2.70$)$ & 0.74 \\
\hline $\begin{array}{l}\text { Amnesia for events } \geq 30 \text { min before injury ( } v \text {. no } \\
\text { amnesia or amnesia for events }<30 \text { min before } \\
\text { injury) }\end{array}$ & $29(28.7)$ & $534(18.7)$ & $1.70(1.10$ to 2.64$)$ & NA \\
\hline $\begin{array}{l}\text { Amnesia for events } \geq 30 \text { min after injury (v. no } \\
\text { amnesia or amnesia for events }<30 \text { min after } \\
\text { injury) }\end{array}$ & $32(31.7)$ & $639(22.4)$ & 1.59 (1.03 to 2.43$)$ & NA \\
\hline $\begin{array}{l}\text { Worsening headache (v. no headache } \\
\text { or stable headache) }\end{array}$ & $\begin{array}{l}n=118 \\
39(33.1)\end{array}$ & $\begin{array}{l}n=3231 \\
584(18.1)\end{array}$ & $2.24(1.51$ to 3.32$)$ & 0.55 \\
\hline Vomiting, $\geq 2$ episodes (v. 0 or 1 episode) & $\begin{array}{l}n=159 \\
77(48.4)\end{array}$ & $\begin{array}{c}n=3707 \\
1505(40.6)\end{array}$ & $1.37(1.00$ to 1.89$)$ & 0.92 \\
\hline Disorientation or confusion & $n=130$ & $n=3378$ & & \\
\hline Any (v. none) & $85(65.4)$ & $1995(59.1)$ & $1.31(0.91$ to 1.89$)$ & 0.59 \\
\hline$>10 \min (v$. none or $\leq 10 \mathrm{~min})$ & $48(36.9)$ & $843(25.0)$ & $1.76(1.22$ to 2.53$)$ & NA \\
\hline Seizure & $n=159$ & $n=3707$ & & \\
\hline Any (v. none) & $7 \quad(4.4)$ & $145(3.9)$ & $1.13(0.52$ to 2.46$)$ & 0.89 \\
\hline $\begin{array}{l}\text { Seizure at time of impact (v. none or late } \\
\text { seizure) }\end{array}$ & $1(0.6)$ & $69(1.9)$ & $0.33(0.05$ to 2.42$)$ & NA \\
\hline
\end{tabular}


$70.3 \%)$. For all seven factors determining the risk for brain injury, the sensitivity was $98.1 \%$ (95\% CI $98.0 \%-98.2 \%$ ) and the specificity was $50.0 \%$ (95\% CI 50.0\%-50.1\%).

\section{Interpretation}

We have developed a clinical decision rule that can be used to identify two levels of risk in children with minor head injury. Patients with any one of four high-risk factors are at significant risk for a need for neurosurgical intervention, whereas patients with any of three additional medium-risk characteristics are at risk of having a brain injury that will be seen on $\mathrm{CT}$. We derived the CATCH rule according to strict methodologic standards and using a large sample of patients. Nevertheless, we intend to prospectively and explicitly validate the rule at multiple sites.
There is considerable disagreement as to the indications for $\mathrm{CT}$ in the large number of head trauma cases classified as minor. ${ }^{26-28}$ Some support routine CT of all patients with minor head injury who have lost consciousness or have amnesia, ${ }^{26}$ wheres others endorse more selective use of CT in cases of minor head injury. ${ }^{27,28}$ Without the support of widely accepted, evidence-based guidelines, physicians are likely to follow the conservative approach of ordering CT for most children with minor head injury seen in an emergency department.

A number of studies have been conducted in the past 10 years to identify a set of high-risk findings that would clearly indicate which children with minor head injury should undergo CT. ${ }^{29-34}$ Unfortunately, those studies have been highly variable in design, and few could be considered robust according to methodologic standards for the development of clinical decision rules. ${ }^{11}$ Interestingly, all of the clinical variables that

Table 3: Association between variables (from history and physical examination) and presence of brain injury in children with a minor head injury (part 2 of 2)

\begin{tabular}{|c|c|c|c|c|}
\hline \multirow[b]{2}{*}{ Variable* } & \multicolumn{2}{|c|}{ Group; no. (\%) of patientst } & \multirow[b]{2}{*}{ OR $(95 \% \mathrm{Cl})$} & \multirow{2}{*}{$\begin{array}{l}\text { Interobserver } \\
\text { agreement, } \\
\text { kappa value } \\
n=333\end{array}$} \\
\hline & $\begin{array}{l}\text { Brain injury } \\
\quad n=159\end{array}$ & $\begin{array}{l}\text { No brain injury } \\
n=3707\end{array}$ & & \\
\hline \multicolumn{5}{|l|}{ From physical examination } \\
\hline Initial Glasgow Coma Scale score & & & & 0.58 \\
\hline 13 & $15(9.4)$ & $80(2.2)$ & 5.55 (3.10 to 9.93$)$ & NA \\
\hline 14 & 30 (18.9) & $252(6.8)$ & $3.52(2.31$ to 5.37$)$ & NA \\
\hline 15 & $114(71.7)$ & $3375(91.0)$ & 1.00 (reference) & NA \\
\hline \multicolumn{5}{|l|}{ Glasgow Coma Scale score } \\
\hline$<15$ at $2 \mathrm{~h}(\mathrm{v} .15$ at $2 \mathrm{~h})$ & $\begin{array}{l}n=104 \\
34(32.7)\end{array}$ & $\begin{array}{l}n=2082 \\
198(9.5)\end{array}$ & 4.62 (2.99 to 7.14$)$ & NA \\
\hline$<15$ at $4 \mathrm{~h} \mathrm{(v.} 15$ at $4 \mathrm{~h})$ & $\begin{array}{l}n=119 \\
15(12.6)\end{array}$ & $\begin{array}{l}n=2404 \\
144(6.0)\end{array}$ & 2.26 (1.28 to 3.99$)$ & NA \\
\hline \multirow[t]{2}{*}{$<15$ at $6 \mathrm{~h}(\mathrm{v} .15$ at $6 \mathrm{~h})$} & $\begin{array}{l}n=114 \\
13(11.4)\end{array}$ & $\begin{array}{l}n=1765 \\
71(4.0)\end{array}$ & 3.07 (1.64 to 5.73$)$ & NA \\
\hline & $n=159$ & $n=3707$ & & \\
\hline $\begin{array}{l}\text { Deterioration in Glasgow Coma Scale score } \\
\text { (v. no deterioration) }\end{array}$ & $55(34.6)$ & $289(7.8)$ & 6.25 (4.42 to 8.86$)$ & NA \\
\hline Pallor (v. no pallor) & $60(37.7)$ & $743(20.0)$ & 2.41 (1.73 to 3.36$)$ & 0.27 \\
\hline Lethargy (v. no lethargy) & $88(55.3)$ & $718(19.4)$ & 5.16 (3.74 to 7.13$)$ & 0.49 \\
\hline Irritability (v. no irritability) & $54(34.0)$ & $365(9.8)$ & 4.70 (3.33 to 6.64$)$ & 0.67 \\
\hline $\begin{array}{l}\text { Suspected open or depressed fracture } \\
\text { (v. no suspicion of open or depressed fracture) }\end{array}$ & $42(26.4)$ & $101(2.7)$ & 12.89 (8.60 to 19.31$)$ & 0.53 \\
\hline Sign of basal skull fracture (v. no sign) & $27(17.0)$ & $63(1.7)$ & 11.79 (7.27 to 19.12$)$ & 0.77 \\
\hline $\begin{array}{l}\text { Unreliability of Glasgow Coma Scale score } \\
\text { because of suspected drug or ethanol use (v. no } \\
\text { suspicion of drug or ethanol use) }\end{array}$ & $4(2.5)$ & $20(0.5)$ & 4.75 (1.60 to 14.07$)$ & 0.79 \\
\hline \multicolumn{5}{|l|}{ Hematoma of the scalp } \\
\hline Any (v. none) & $114(71.7)$ & $1142(30.8)$ & 5.69 (4.00 to 8.09$)$ & 0.61 \\
\hline $\begin{array}{l}\text { Large, boggy hematoma (v. none or small, } \\
\text { localized hematoma) }\end{array}$ & $59(37.1)$ & $197(5.3)$ & 10.51 (7.39 to 14.95$)$ & 0.70 \\
\hline
\end{tabular}

Note: $\mathrm{Cl}=$ confidence interval, $\mathrm{NA}=$ not applicable, $\mathrm{OR}=$ odds ratio, $\mathrm{SD}=$ standard deviation.

*All variables are binary, with comparator group as indicated, except for initial score on Glasgow Coma Scale.

tUnless otherwise indicated.

$\neq$ Value reported is mean difference $(95 \% \mathrm{Cl})$. 
make up the $\mathrm{CATCH}$ rule have been found to be significant predictors of intracranial injury and have been part of clinical decision rules developed in previous studies: Glasgow Coma Scale score less than 15 at two hours, ${ }^{30-33}$ suspected open or depressed skull fracture, ${ }^{30-33}$ worsening headache, ${ }^{29,30}$ persistent irritability, ${ }^{31}$ sign of basal skull fracture, ${ }^{30-33}$ large, boggy scalp hematoma ${ }^{31,32}$ and dangerous mechanism of injury. ${ }^{32,33}$

We believe that an accurate decision rule could stabilize or reduce the number of children undergoing CT, thereby minimizing both health care costs and children's exposure to the

Table 4: Association between variables related to mechanism of injury and presence of brain injury in children with a minor head injury

\begin{tabular}{|c|c|c|c|}
\hline \multirow[b]{2}{*}{ Variable* } & \multicolumn{2}{|c|}{ Group; no. (\%) of patients } & \multirow[b]{2}{*}{ OR $(95 \% \mathrm{Cl})$} \\
\hline & $\begin{array}{l}\text { Brain injury } \\
\quad n=159\end{array}$ & $\begin{array}{l}\text { No brain injury } \\
n=3707\end{array}$ & \\
\hline \multicolumn{4}{|l|}{ Mechanism of injury } \\
\hline $\begin{array}{l}\text { Fall from elevation }<3 \mathrm{ft}(<91 \mathrm{~cm}) \text { above ground or } \\
<5 \text { stairs (reference category) }\end{array}$ & $11(6.9)$ & $1018(27.5)$ & 1.00 (reference) \\
\hline $\begin{array}{l}\text { Fall from elevation } 3-10 \mathrm{ft}(91-305 \mathrm{~cm}) \text { above } \\
\text { ground or } \geq 5 \text { stairs }\end{array}$ & $54(34.0)$ & $584(15.8)$ & $8.56(4.44-16.50)$ \\
\hline Fall from elevation $>10 \mathrm{ft}(>305 \mathrm{~cm})$ above ground & $10(6.3)$ & $39(1.1)$ & $23.73(9.51-59.20)$ \\
\hline Fall from bicycle & $12(7.5)$ & $282(7.6)$ & $3.94(1.72-9.02)$ \\
\hline Fall from moving motor vehicle & $2(1.3)$ & $14(0.4)$ & $13.22(2.68-65.24)$ \\
\hline Motor vehicle collision & $12(7.5)$ & $103(2.8)$ & $10.78(4.64-25.05)$ \\
\hline Injury involving other type of motorized vehicle & $7(4.4)$ & $76(2.1)$ & $8.52(3.21-22.62)$ \\
\hline Bicycle collision with car & $6(3.8)$ & $34(0.9)$ & $16.33(5.71-46.75)$ \\
\hline Pedestrian struck by car & $11(6.9)$ & $122(3.3)$ & $8.34(3.54-19.65)$ \\
\hline Pedestrian struck by bicycle & 0 & $6(0.2)$ & - \\
\hline Assault with fist or feet & $1(0.6)$ & $82(2.2)$ & $1.13(0.14-8.85)$ \\
\hline Assault with blunt object & $4(2.5)$ & $15(0.4)$ & $24.68(7.05-86.38)$ \\
\hline Sports & $10(6.3)$ & 509 (13.7) & $1.82(0.77-4.31)$ \\
\hline Contact sports (axial load) & $2(1.3)$ & $349(9.4)$ & $0.53(0.12-2.40)$ \\
\hline Diving & 0 & $2(0.1)$ & - \\
\hline Head struck by blunt object & $11(6.9)$ & $114(3.1)$ & $8.93(3.79-21.06)$ \\
\hline Hit object head on & $5(3.1)$ & $317(8.6)$ & $1.46(0.50-4.23)$ \\
\hline Other & 0 & $23(0.6)$ & - \\
\hline Unknown & $1(0.6)$ & $18(0.5)$ & $5.14(0.63-41.96)$ \\
\hline Dangerous mechanismt (v. other mechanism) & $113(71.1)$ & $1087(29.3)$ & $5.92(4.17-8.40)$ \\
\hline $\begin{array}{l}\text { No seat belt ( } v \text {. seat belt in use) in motor vehicle } \\
\text { collision }\end{array}$ & $\begin{array}{l}n=12 \\
2(16.7)\end{array}$ & $\begin{array}{l}n=103 \\
35(34.0)\end{array}$ & $0.39(0.08-1.92)$ \\
\hline Bicycle helmet used ( $v$. helmet not used) & $\begin{array}{l}n=17 \\
2(11.8)\end{array}$ & $\begin{array}{c}n=265 \\
124(46.8)\end{array}$ & $0.15(0.03-0.68)$ \\
\hline \multirow[t]{2}{*}{ Motor vehicle collision ( $v$. other mechanism) } & $\begin{array}{l}n=159 \\
12(7.5)\end{array}$ & $\begin{array}{r}n=3707 \\
103(2.8)\end{array}$ & $2.86(1.54-5.31)$ \\
\hline & $n=12$ & $n=103$ & \\
\hline Ejected (v. not ejected) & $2(16.6)$ & $9(8.7)$ & $1.78(0.34-9.42)$ \\
\hline Roll-over (v. no roll-over) & $3(25.0)$ & $35(34.0)$ & $0.71(0.17-2.93)$ \\
\hline $\begin{array}{l}\text { Death of another person in same motor vehicle } \\
\text { collision ( } v \text {. no deaths in the collision) }\end{array}$ & 0 & $7(6.8)$ & - \\
\hline Head-on collision (v. all other types of collision) & $1(8.3)$ & $5(4.9)$ & $1.58(0.17-14.92)$ \\
\hline $\begin{array}{l}\text { Simple rear-end collision (v. all other types of } \\
\text { collision) }\end{array}$ & 0 & $10(9.7)$ & - \\
\hline $\begin{array}{l}\text { Highway speed (i.e., } 60-100 \mathrm{~km} / \mathrm{h} \text { ) (v. speed } \\
<60 \mathrm{~km} / \mathrm{h} \text { ) }\end{array}$ & $3(25.0)$ & $11(10.7)$ & $2.70(0.63-11.49)$ \\
\hline
\end{tabular}

Note: $\mathrm{Cl}=$ confidence interval, $\mathrm{OR}=$ odds ratio

*All variables are binary, with comparator group as indicated, except for mechanism of injury.

†Motor vehicle related, fall from elevation $>3 \mathrm{ft}(>91 \mathrm{~cm})$ or $>5$ stairs, fall from bicycle with no helmet. 
potentially harmful effects of ionizing radiation. There is growing concern that early exposure to ionizing radiation may result in a substantial rise in lifetime risk of fatal cancer.

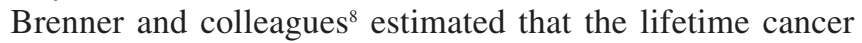
mortality risk attributable to the ionizing radiation to which a one-year-old child would be exposed through a single CT scan of the head was about 1 in 1500; they estimated the corresponding mortality risk for 10-year-olds as about 1 in 5000 . In addition, Hall and others ${ }^{9}$ recently reported that low doses of ionizing radiation to the brain in infancy may influence cognitive abilities in adulthood. These risks may be small for a given individual, but when applied to a large population they may create a substantial public health risk.

\section{Limitations}

Our study had potential limitations. For ethical reasons, not all enrolled children with minor head injury underwent CT. Nonetheless, we are confident that the children who did not undergo CT received a full assessment for the primary outcome measure, the need for neurologic intervention. All of the study patients who were not examined by CT did undergo a structured and validated telephone interview at 14 days for determination of the proxy outcome measure. Any patient who could not be completely and adequately followed was excluded from the study analyses. Although not all children with minor head injury seen at the study sites during the study period were enrolled in the study, this situation is not out of the ordinary for a clinical study, and we could not determine any systematic difference between the patients who were enrolled and those who were not enrolled. We enrolled relatively few children under two years of age $(n=277)$, and we identified only 23 cases of brain injury in this group. Although the CATCH rule correctly identified all these cases of brain injury, further prospective study of this subgroup is required, as children under two years of age may have more subtle presentations of head injury than older children. ${ }^{28,35}$

Some may question the significance of relatively small lesions found on the CT scans. In our study we defined as significant any intracranial bleeding or contusion seen on CT, no matter how small, as well as isolated pneumocephalus seen on CT. We consulted several Canadian aca-

Table 5: Performance of the four high-risk factors in the CATCH rule in relation to need for neurologic intervention in children with a minor head injury

\begin{tabular}{lcc}
\hline Result & $\begin{array}{c}\text { Needed } \\
\text { neurologic } \\
\text { intervention }\end{array}$ & $\begin{array}{c}\text { Did not need } \\
\text { neurologic } \\
\text { intervention }\end{array}$ \\
\hline Positive ( $\geq 1$ high-risk factors) & 24 & 1144 \\
\hline Negative (no high-risk factors) & 0 & 2698 \\
Sensitivity, \% (95\% Cl) & $100.0(86.2-100.0)$ \\
Specificity, \% (95\% Cl) & \multicolumn{2}{c}{$70.2(68.8-71.6)$} \\
$\begin{array}{l}\text { \% of patients who would } \\
\text { undergo CT scanning }\end{array}$ & \multicolumn{2}{c}{30.2} \\
\hline
\end{tabular}

Note: $\mathrm{CATCH}=$ Canadian Assessment of Tomography for Childhood Head injury, $\mathrm{Cl}=$ confidence interval, $\mathrm{CT}$ = computed tomography.

\section{Box 1: Canadian Assessment of Tomography for} Childhood Head injury: the CATCH rule

$\mathrm{CT}$ of the head is required only for children with minor head injury* and any one of the following findings:

\section{High risk (need for neurologic intervention)}

1. Glasgow Coma Scale score $<15$ at two hours after injury

2. Suspected open or depressed skull fracture

3. History of worsening headache

4. Irritability on examination

Medium risk (brain injury on CT scan)

5. Any sign of basal skull fracture (e.g., hemotympanum, "raccoon" eyes, otorrhea or rhinorrhea of the cerebrospinal fluid, Battle's sign)

6. Large, boggy hematoma of the scalp

7. Dangerous mechanism of injury (e.g., motor vehicle crash, fall from elevation $\geq 3 \mathrm{ft}[\geq 91 \mathrm{~cm}]$ or 5 stairs, fall from bicycle with no helmet)

Note: $\mathrm{CT}=$ computed tomography.

*Minor head injury is defined as injury within the past 24 hours associated with witnessed loss of consciousness, definite amnesia, witnessed disorientation, persistent vomiting (more than one episode) or persistent irritability (in a child under two years of age) in a patient with a Glasgow Coma Scale score of 13-15.

demic pediatric neurosurgeons, all of whom felt that any abnormality caused by acute trauma is important in children. However, we recognize that there is no consensus among health care professionals on this issue. Additional studies are needed to evaluate the clinical significance of these very small lesions and to evaluate whether finding them justifies the risk associated with exposing the child to radiation. Finally, before it can be used in clinical practice, this derived rule must be prospectively validated to determine its accuracy, its acceptability to clinicians and its impact on care in a new patient population. ${ }^{36,37}$

\section{Conclusion}

The CATCH rule is a sensitive, prospectively derived clinical decision rule that has the potential to both standardize the need for CT and reduce the number of CT scans performed for children with minor head injury. Further studies are required to prospectively validate this rule in other pediatric cohorts.

Table 6: Performance of all seven risk factors in the CATCH rule in relation to the presence of brain injury on CT scan in children with a minor head injury

\begin{tabular}{lcc}
\hline Result & $\begin{array}{c}\text { Had brain } \\
\text { injury on } \\
\text { CT scan }\end{array}$ & $\begin{array}{c}\text { Did not have } \\
\text { brain injury } \\
\text { on CT scan }\end{array}$ \\
\hline Positive ( $\geq 1$ risk factors) & 156 & 1851 \\
\hline Negative (no risk factors) & 3 & 1856 \\
Sensitivity, \% (95\% Cl) & \multicolumn{2}{c}{$98.1(94.6-99.4)$} \\
$\begin{array}{l}\text { Specificity, \% (95\% Cl) } \\
\text { \% of patients who would } \\
\text { undergo CT scanning }\end{array}$ & \multicolumn{2}{c}{$50.1(48.5-51.7)$} \\
\hline
\end{tabular}

Note: $\mathrm{CATCH}=$ Canadian Assessment of Tomography for Childhood Head injury, $\mathrm{Cl}=$ confidence interval, $\mathrm{CT}=$ computed tomography. 
This article has been peer reviewed.

Competing interests: None declared. George Wells is a biostatistical consultant for $C M A J$ and was not involved in the editorial decision-making process for this article.

Contributors: All of the authors contributed to the conceptual design of the study. Rhonda Correll, Anna Jarvis, Gary Joubert, Benoit Bailey, Laurel Chauvin-Kimoff, Martin Pusic, Don McConnell, Cheri Nijssen-Jordan, Norm Silver and Brett Taylor contributed to the acquisition of data. Martin Osmond, Terry Klassen, George Wells and Ian Stiell contributed to the analysis and interpretation of the data and to drafting the manuscript. All of the authors critically reviewed the article for important intellectual content and approved the final version submitted for publication.

Acknowledgements: The authors thank the other members of the Pediatric Emergency Research Canada (PERC) Head Injury Study Group, Dr. Martin Reed (University of Manitoba), Dr. Keith Aronyk (University of Alberta), Dr. Michael Vassilyadi (University of Ottawa) and Dr. Mark Hamilton (University of Calgary), for their assistance with study design and interpretation of data. We thank the following for their much-appreciated assistance as the study coordinators at each site: Jennifer Spruyt, Eleanor Fitzpatrick, Rita Arsenault, Bev Irwin, Rose Jacobson, Sue Heathcote, Lanna Bryksa, Nathalie Franc, Geri St Jean and Diane Laforte. The authors thank My-Linh Tran and Sheryl Domingo for managing the data. The authors also thank all of the physicians, nurses and clerks at the study sites who voluntarily assisted in identifying cases and collecting data.

Funding: This study was funded by peer-reviewed grants from the Canadian Institutes of Health Research (CIHR funding reference number MOP-43911), the Emergency Health Services Branch of the Ontario Ministry of Health and Long-Term Care and the Alberta Children's Hospital Foundation.

\section{REFERENCES}

1. Teasdale G, Jennett B. Assessment of coma and impaired consciousness: a practical scale. Lancet 1974;2:81-4.

2. Connors JM, Ruddy RM, McCall J, et al. Delayed diagnosis in pediatric blunt trauma. Pediatr Emerg Care 2001;17:1-4.

3. Tran T, McGuire T, Malcolm C, et al. Incidence of delayed intracranial hemorrhage in children with an uncomplicated minor head injury [abstract]. Pediatr Res 2002;50:83.

4. Galbraith S. Misdiagnosis and delayed diagnosis in traumatic intracranial haematoma. BMJ 1976;1:1438-9.

5. Klassen TP, Reed MH, Stiell IG, et al. Variation in utilization of computed tomography scanning for the investigation of minor head trauma in children: a Canadian experience. Acad Emerg Med 2000;7:739-44.

6. Osmond MH, Klassen TP, Stiell IG, et al.; CATCH Study Group. The CATCH rule: a clinical decision rule for the use of computed tomography of the head in children with minor head injury [abstract]. Acad Emerg Med 2006;13:S11.

7. Davis RL, Mullen N, Makela M, et al. Cranial computed tomography scans in children after minimal head injury with loss of consciousness. Ann Emerg Med 1994; 24:640-5.

8. Brenner D, Elliston CD, Hall EJ, et al. Estimated risks of radiation-induced fatal cancer from pediatric CT. AJR Am J Roentgenol 2001;176:289-96.

9. Hall $\mathrm{P}$, Adami H, Trichopoulos D, et al. Effect of low doses of ionising radiation in infancy on cognitive function in adulthood: Swedish population based cohort study. BMJ 2004;328:19.

10. Laupacis A, Sekar N, Stiell IG. Clinical prediction rules: a review and suggested modifications of methodological standards. JAMA 1997;277:488-94.

11. Stiell IG, Wells GA. Methodologic standards for the development of clinical decision rules in emergency medicine. Ann Emerg Med 1999;33:437-47.

12. Plint AC, Bulloch B, Osmond MH, et al. Validation of the Ottawa Ankle Rules in children with ankle injuries. Acad Emerg Med 1999;6:1005-9.
13. Bulloch B, Neto G, Plint A, et al. Validation of the Ottawa Knee Rule in children: a multicenter study [published erratum in Ann Emerg Med 2004;43:142]. Ann Emerg Med 2003;42:48-55.

14. Stiell IG, Greenberg GH, McKnight RD, et al. A study to develop clinical decision rules for the use of radiography in acute ankle injuries. Ann Emerg Med 1992;21:384-90.

15. Stiell IG, Greenberg GH, McKnight RD, et al. Decision rules for the use of radiography in acute ankle injuries: refinement and prospective validation. JAMA 1993;269:1127-32.

16. Stiell IG, McKnight RD, Greenberg GH, et al. Implementation of the Ottawa Ankle Rules. JAMA 1994;271:827-32.

17. Stiell I, Wells G, Laupacis A, et al. A multicentre trial to introduce clinical decision rules for the use of radiography in acute ankle injuries. BMJ 1995;311:594-7.

18. Stiell IG, Greenberg GH, Wells GA, et al. Derivation of a decision rule for the use of radiography in acute knee injuries. Ann Emerg Med 1995;26:405-13.

19. Stiell IG, Greenberg GH, Wells GA, et al. Prospective validation of a decision rule for the use of radiography in acute knee injuries. JAMA 1996;275:611-5.

20. Stiell IG, Wells GA, Hoag RA, et al. Implementation of the Ottawa Knee Rule for the use of radiography in acute knee injuries. JAMA 1997;278:2075-8.

21. Stiell IG, Wells GA, Vandemheen K, et al. The Canadian CT Head Rule for patients with minor head injury. Lancet 2001;357:1391-6.

22. Stiell IG, Clement CM, Rowe BH, et al. Comparison of the Canadian CT Head Rule and the New Orleans Criteria in patients with minor head injury. JAMA 2005;294:1511-8.

23. Stiell IG, Wells GA, Vandemheen KL, et al. The Canadian Cervical Spine Radiography Rule for alert and stable trauma patients. JAMA 2001;286:1841-8

24. Stiell IG, Clement CM, McKnight RD, et al. The Canadian C-Spine Rule versus the NEXUS low-risk criteria in patients with trauma. $N$ Engl $\mathrm{J} \mathrm{Med}$ 2003;349:2510-8.

25. Efron B, Tibshirani R. An introduction to the bootstrap. London (UK): Chapman and Hall; 1993.

26. Stein SC, Ross SE. Mild head injury: a plea for routine early CT scanning. $J$ Trauma 1992;33:11-3.

27. Advanced trauma life support for doctors; student course manual. 8th ed. Chicago (IL): American College of Surgeons; 2008.

28. American Academy of Pediatrics, Committee on Quality Improvement. The management of minor closed head injury in children. Pediatrics 1999;104:1407-15

29. Haydel MJ, Shembekar AD. Prediction of intracranial injury in children aged five years and older with loss of consciousness after minor head injury due to nontrivial mechanisms. Ann Emerg Med 2003;42:507-14.

30. Palchak MJ, Holmes JF, Vance CW, et al. A decision rule for identifying children at low risk for brain injuries after blunt head trauma. Ann Emerg Med 2003;42: 492-506.

31. Oman JA, Cooper RJ, Holmes JF, et al. Performance of a decision rule to predict need for computed tomography among children with blunt head trauma. Pediatrics 2006; $117: \mathrm{e} 238-46$

32. Dunning J, Daly JP, Lomas JP, et al. Derivation of the children's head injury algorithm for the prediction of important clinical events decision rule for head injury in children. Arch Dis Child 2006;91:885-91.

33. Atabaki SM, Stiell IG, Bazarian JJ, et al. A clinical decision rule for cranial computed tomography in minor pediatric head trauma. Arch Pediatr Adolesc Med 2008;162:439-45.

34. Maguire JL, Boutis K, Uleryk EM, et al. Should a head-injured child receive a head CT scan? A systematic review of clinical prediction rules. Pediatrics 2009; 124:e145-54

35. Schutzman SA, Barnes P, Duhaime A, et al. Evaluation and management of children younger than two years old with apparently minor head trauma: proposed guidelines. Pediatrics 2001;107:983-93.

36. Wasson JH, Sox HC, Neff RK, et al. Clinical prediction rules: application and methodological standards. N Engl J Med 1985;313:793-9.

37. Charlson ME, Ales KL, Simon R, et al. Why predictive indexes perform less well in validation studies. Arch Intern Med 1987;147:2155-61.

Correspondence to: Dr. Martin Osmond, Department of

Pediatrics, Children's Hospital of Eastern Ontario, 401 Smyth Rd., OttawaON K1H8L1; osmond@cheo.on.ca 